\title{
9 - Técnicas utilizadas na análise de causa raiz - O Protocolo de Londres
}

\author{
Celsa Raquel Villaverde Melgarejo \\ Patricia de Carvalho Mastroianni \\ Fabiana Rossi Varallo
}

\section{SciELO Books / SciELO Livros / SciELO Libros}

MELGAREJO, C. R. V., MASTROIANNI, P. C., and VARALlO, F. R.

Técnicas utiliza das na análise de causa raiz - O Protocolo

de Londres. In.: Promoção da cultura de notificação de incidentes em saúde [online]. São Paulo: Editora UNESP, 2019, pp. 43-45. ISBN:

9788595463370. https://doi.org/10.7476/9788595463370.0011.

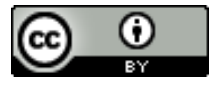

All the contents of this work, except where otherwise noted, is licensed under a $\underline{\text { Creative Commons Attribution } 4.0 \text { International license. }}$

Todo o conteúdo deste trabalho, exceto quando houver ressalva, é publicado sob a licença Creative Commons Atribição 4.0.

Todo el contenido de esta obra, excepto donde se indique lo contrario, está bajo licencia de la licencia Creative Commons Reconocimento 4.0. 


\section{9}

\section{TÉCNICAS UTILIZADAS NA ANÁLISE DE CAUSA RAIZ - O PROTOCOLO DE LONDRES}

O Protocolo de Londres (PL) advém de uma versão atualizada e revisada de um documento denominado "Protocolo para investigação e análise de incidentes clínicos", amplamente divulgado e utilizado como guia para gerenciar riscos estabelecidos na aviação, indústrias de petróleo e nuclear, em que as investigações de acidentes é uma rotina. A análise de investigação está embasada no modelo organizacional de acidentes proposto por James Reason (2000), no qual barreiras para evitar acidentes são estabelecidas para mitigar as consequências decorrentes das falhas, e as decisões são tomadas hierarquicamente (Luengas Amaya, 2009).

A relevância do Protocolo de Londres está na busca de fatores contribuintes para ocorrência de incidentes e near misses, induzindo perguntas sobre o porquê de um incidente, uma vez que somente a identificação da falha está aquém de ser um modelo de investigação, pois não identifica a cadeia de erros que culminaram no incidente. Além do mais, o protocolo não foca o indivíduo como precursor e único responsável pelo erro, mas apura as causas como fatores organizacionais preexistentes que proporcionaram a chance para a ocorrência de erros (Taylor-Adams; Vincent, 2004; Vincent, 2003). 
Pelo Protocolo de Londres é possível avaliar fatores relacionados ao paciente, como condição clínica e características pessoais; existência de protocolos, procedimentos e processos, como tarefas; falhas de equipamentos, maquinários ou insumos relacionados à saúde; problemas de sobrecarga de trabalho, como fator ambiental; deficiência de comunicação entre equipes; condição organizacional; pressão ou recurso financeiro; condições estruturais relacionadas às habilidades; conhecimento técnico e conduta dos profissionais de saúde, dentre outros (Quadro 6). O objetivo principal é a reconstrução de todas as situações que levaram ao incidente por meio de um brainstorm informal com todos os envolvidos e seus líderes (Taylor-Adams; Vincent, 2004)

Quadro 6 - Fatores que podem contribuir para ocorrência de incidentes conforme o Protocolo de Londres.

\begin{tabular}{|c|c|}
\hline Tipo de fator & Fator contribuinte ou influenciador \\
\hline Paciente & $\begin{array}{l}\text { Condição física e clínica (complexidade, gravidade). } \\
\text { Comunicação e linguagem (compreensão). } \\
\text { Fatores sociais e de personalidade, como excesso de con- } \\
\text { fiança, comportamento negligente, fatores emocionais. }\end{array}$ \\
\hline Tarefa & $\begin{array}{l}\text { Estrutura e desenho da tarefa. } \\
\text { Disponibilidade e uso de protocolos. } \\
\text { Auxílio na tomada de decisão. } \\
\text { Clareza e estrutura da tarefa. }\end{array}$ \\
\hline $\begin{array}{l}\text { Individuais } \\
\text { (profissional da } \\
\text { saúde) }\end{array}$ & $\begin{array}{l}\text { Falta de conhecimento e habilidade, descuido, desaten- } \\
\text { ção, violação de rotinas e normas, não compreensão das } \\
\text { orientações, competência, saúde física e mental. }\end{array}$ \\
\hline Equipes & $\begin{array}{l}\text { Falha na comunicação verbal e escrita. } \\
\text { Ausência de anotações, informações ilegíveis (prontuá- } \\
\text { rio, ficha do paciente). } \\
\text { Disponibilidade de ajuda e supervisão. } \\
\text { Estrutural (congruência, liderança, dentre outros). }\end{array}$ \\
\hline $\begin{array}{l}\text { Ambientais e de } \\
\text { trabalho }\end{array}$ & $\begin{array}{l}\text { Nivelamento e habilidades do staff. } \\
\text { Padrões de turno, carga de trabalho. } \\
\text { Manutenção e disponibilidade de materiais e equipa- } \\
\text { mentos. } \\
\text { Apoio gerencial e administrativo. } \\
\text { Área física/infraestrutura. }\end{array}$ \\
\hline
\end{tabular}




\begin{tabular}{cl}
\hline Tipo de fator & \multicolumn{1}{c}{ Fator contribuinte ou influenciador } \\
\hline & Recursos financeiros. \\
& Estrutura organizacional. \\
Gestão & Políticas, padrões e objetivos. \\
organizacional e & Cultura de segurança e prioridades. \\
institucional & Contexto regulatório e econômico. \\
& Sistema de saúde. \\
& Ligação com organizações externas. \\
\hline
\end{tabular}

Fonte: Adaptado de Taylor-Adams; Vincent (2004). 